\title{
COM QUE PALETAS SE PINTA O AUTOEROTISMO DAS MULHERES? EXPRESSÕES DA LITERATURA DE AUTORIA FEMININA EM “MESTRE GOSHKA” (1996) DE ADRIANA LUNARDI
}

Fabrícia dos Santos Silva Martins Fernanda Lázara de Oliveira Santos

Silvana Augusta Barbosa Carrijo

Resumo: Este trabalho pretende refletir sobre as expressões da literatura brasileira contemporânea de autoria feminina a partir do conto "Mestre Goshka" (1996), da escritora catarinense Adriana Lunardi. Pretendemos observar, sobretudo, em que medida o projeto estético desta narrativa concorre para romper as barreiras instituídas nos campos estético e ideológico. Refletiremos, ainda, sobre como se associam as manifestações da linguagem e da literatura a elementos da história e da cultura nas configurações das identidades individuais e coletiva das mulheres.

Palavras-chave: Autoria feminina; Erotismo; Representação feminina. Adriana Lunardi.

Abstract: This article focuses on analyzing the Brazilian female contemporary literary expressions based on the tale "Mastre Goshka" by Adriana Lunardi, a writer born in the Brazilian State of Santa Catarina. The main goal of this article is to observe how the literary aesthetics in the narrative of the tale break new grounds in order to estabilish new ideological and aesthetic values. Another point estudied here is about the manifestations of Language and Literature and its link to historical and cultural elements in the context of female individual and colective identities.

Keywords: Female authorship; Eroticism; Female representation.

\section{SOBRE OS RASTROS FEMININOS NA LITERATURA}

O campo da literatura brasileira contemporânea tem sido composto por produções notoriamente valorosas. A 
tarefa de comprovar esta afirmativa parece-nos possível quando observamos os títulos publicados pelas editoras que possuem maior visibilidade no Brasil atualmente. Conforme nos aponta Regina Dalcastagnè (2012) em sua pesquisa que resulta num mapa do território da literatura brasileira hodierna, as editoras centrais para a ficção brasileira são a Rocco, Companhia das Letras e a Record. No rol de publicações dessas editoras, é possível encontrarmos produções literárias robustas assinadas por escritoras que elegem temáticas várias para expressar, através das narrativas de ficção, a materialização de descentramentos e multiplicidades que se distanciam da lógica convencional das narrativas tradicionais.

Essa tendência aparece com recorrência em obras de autoras tais que Carolina Maria de Jesus, Lya Luft, Marina Colasanti, Fernanda Young, Elvira Vigna, e tantas outras, dentre as quais salta aos nossos olhos a tessitura de Adriana Lunardi. Nascida na cidade de Xaxim - SC -, a escritora dá início à sua carreira literária como contista em 1996, publicando As meninas da Torre Helsinque, obra inaugural que the rendeu os prêmio Fumproarte (1996) e o prêmio Açorianos de Literatura (1997). Em 2002 publica a coletânea de contos Vésperas, indicada ao prêmio Jabuti (2003). Posteriormente às publicações dos contos, Lunardi 
adentra o território dos romances com Corpo Estranho (2006), A Vendedora de fósforos (2011) e a novela A longa estrada dos ossos (2014). Para além de contos e romances, a autora assina também participações em antologias, tais que O livro das mulheres (1999), 25 mulheres que estão fazendo a nova literatura brasileira (2002), Contos sobre tela (2005). Dentre questões várias, sua produção literária revela procedimentos estéticos que sugerem, entre outras questões, a manipulação do texto literário como espaço de afirmação da autenticidade da autoria feminina. Ler as mulheres ficcionalizadas através da percepção de outra mulher, cujas experiências podem ou não se entrelaçarem com sua produção literária, propicia recuperar e valorizar as histórias escritas no feminino, possibilitando-nos conhecer narrativas que nos são apresentadas pelas vozes delas.

Embora haja questionamentos e olhares judicativos sobre as produções de autoria feminina, a qualidade estética e literária de grande parte desses escritos tem se confirmado largamente no decorrer dos tempos por meio dos inúmeros estudos que vêm sendo divulgados no campo da crítica literária. A literatura desenvolvida por mãos femininas envolve o gênero humano, explorando temas universais e necessários; o que a diferencia é apenas a alteração do ponto 
de vista acerca dessas temáticas, o que expõe certamente questões antropológicas socioeconômicas e culturais, possibilitando diferentes percepções (TEIXEIRA, 2008).

Em se tratando da recepção do texto, na obra intitulada Sobre a desconstrução (1997), Jonathan Culler trata da diferenciação de atitudes do leitor homem para a leitora mulher, o que evidencia a relevância de se considerar o ponto de vista feminino para o público leitor, visto que a literatura se centrou por séculos na visão masculina e falocêntrica. Culler deixa claro em suas afirmações a importância da representação da mulher pelos olhos de uma diç̧ão feminina, uma vez que, tendo modos diferenciados de enfrentamento e divergentes posturas acerca das mesmas situações, essa representação gera, por consequência, a cumplicidade dos pares. Os universos do masculino e feminino são distintos, inegavelmente, seja em conjunturas gerais moldadas por todas as influências dos largamente impostos modelos patriarcais, seja pela sensibilidade de ver o mundo sob diversificadas perspectivas, como no caso do conto de Lunardi.

A representação sob o olhar do outro pode comprometer a narrativa e por consequência gerar um retrato degradado da situação feminina (CULLER, 1997). Ao escrever, uma 
mulher cria seu espaço de enunciação, desfazendo o silenciamento que por séculos nos fora imposto. Para Zinani (2011), "essa atitude, além do caráter simbólico que traz incluso, também institui um espaço de poder: o poder de dizer e de se dizer" (ZINANI, 2011, p. 5). Por meio dessa cumplicidade de pares a qual nos referimos, as escritoras têm a chance de se engendrar por esse campo tão sensível.

Em se tratando da escritura feminina há outro aspecto relevante para se ponderar, a questão da linguagem. Nas palavras de Zinani, nem mesmo as estruturas linguísticas e as escolhas lexicais têm o mesmo teor quando analisamos escritores e escritoras:

Em relação à linguagem, estudos comprovam que estruturas linguísticas, seleção lexical, mesmo aplicação de fórmulas de polidez e utilização de turnos de fala não são aproveitados da mesma maneira por homens e mulheres. $O$ estudo do emprego da língua pelas mulheres faz parte de um amplo projeto que procura assinalar as marcas linguísticas características dos gêneros. É por meio da linguagem que o mundo é nomeado e categorizado, entendido e interpretado, cabendo, assim, à mulher a reinvenção e a desconstrução do discurso opressor masculino. (ZINANI, 2011, p. 6)

Desse modo, por meio da literatura, as mulheres reforçam o processo de reinvenção e desarticulação dos discursos 
arraigados por meio do texto literário e, nesse contexto, a palavra escrita passa a ser uma ferramenta perspicaz e eficiente, o que é nítido, já que estamos lidando com o exercício da linguagem pela palavra escrita. Em se tratando do discurso, renomeamos e categorizamos um universo distinto, exercendo largamente esse poder de desconstrução. Tal qual analisaremos na obra posta em tela neste trabalho, ter contato com a descrição das experiências da vida por meio de locutor feminino valida nossas próprias percepções, enquanto a exploração contrária, por vezes, pode ser rasa e menos simbólica.

Indo ao encontro de todas essas novas perspectivas, as narrativas contemporâneas escritas por mulheres têm demonstrado sujeitos descentrados e moventes, frequentemente femininos, que vivenciam histórias demarcadoras da complexidade do ser humano do sexo feminino, o que permite a representação das mulheres com mais autenticidade. Isso porque, ao observarmos a historiografia, percebemos que as mulheres foram, predominantemente, escritas e representadas pela perspectiva do autor - o homem escritor. Isso implica a constituição de personagens femininas delineadas a partir da idealização masculina. Observando este fato, de modo muito pertinente, as pesquisadoras Lúcia Castello Branco e 
Ruth Santiago Brandão fazem uso de uma perfeita analogia para ilustrar esta circunstância perceptível em grande parte dos escritos de autoria masculina. Segundo elas, "a figura feminina é fina voz retirada de um registro masculino e se constrói de forma similar a do ventríloquo e seu boneco: confusão de vozes, perversa construção enganosa [...]!" (BRANDÃO, 2004, p. 16).

Interditadas na fala e, consequentemente na escrita, destinadas ao cumprimento de papeis sociais desvinculados da erudição, as mulheres estiveram, por muito tempo, completamente à margem do campo artístico-literário. Reduzidas às funções do lar e da maternidade, não tiveram voz e espaço para contornar os impedimentos. Ainda que esta fase de silenciamento esteja em processo de superação, não se desfaz o fato de que, em decorrência disso, ao olharmos novamente para o passado, deparamo-nos com um conjunto impenetrável por novas incursões, sobretudo de mulheres escritoras, de obras canonizadas.

Norma Telles (1987) observa que é a partir destes interditos que as escritoras do Oitocentismo em diante terão de elaborar seus textos, contornando os obstáculos e valendo-se de estratégias para que suas vozes sejam reverberadas. Embora esse processo de conquista ganhe 
força, paulatinamente, conforme mudanças ocorridas nas leis, na sociedade e na cultura, observamos, ainda no início do século XIX, uma escrita de autoria feminina atrelada ao estigma do romance sentimental ou ressentido, de uma dicção que fazia do texto literário seu lugar de manifestar insatisfações com a vida doméstica.

Dadas as poucas possibilidades de exploração do potencial criativo das escritoras do passado, há que se admitir que, conforme já apontava Virginia Woolf em Mulheres e ficção $(1929)^{1}$, a prática da escrita feminina, já em meados do século $X X$, é um progresso em relação à antiga pelo que foi sendo conquistado pelas mulheres na sociedade. Ressaltese que, mesmo em face de grandes vitórias que trouxeram a nós, mulheres, a inserção no campo artístico e intelectual e, por conseguinte, o reconhecimento da contribuição feminina para a cultura e a literatura no século $X X$, ainda estamos em menor número com relação a publicações dos autores. A pesquisadora Regina Dalcastagnè (2010) na obra Representações irrestritas: a mulher no romance brasileiro contemporâneo, apresenta uma pesquisa em que são analisados 130 romances brasileiros lançados no início dos anos 2000, dentre os quais apenas 31 títulos são escritos por

1 Este texto se trata de um artigo publicado pela primeira vez no número de mar. 1929 da revista Forum, de Nova York. A referência feita por nós neste estudo trata-se de uma reedição do ano de 2019. 
mulheres, isto é, 23,8\%. Segundo a autora, apesar da evolução da condição feminina, a escrita de romances continua sendo uma atividade predominantemente masculina.

Desse modo, a inserção de novos nomes e outras vozes no campo da narrativa de ficção é, para além de uma necessidade, uma maneira de abalar as bases do instituído nos campos teórico, político e social de modo que se possa colocar a mulher como sujeito na reescrita de suas histórias silenciadas e/ou apagadas no decorrer do tempo; é entremear no tecido do texto ficcional a potencialidade criativa que faz emergir a desconstrução dos caminhos antes trilhados, revelando sendas que não foram percorridas.

Privilegiar a apreciação crítica de escritoras contemporâneas, sobretudo aquelas que tecem narradoras e não apenas personagens, tal como na obra eleita para esta análise, permitem modos de enxergar a representação do feminino em suas mais diversas fases e faces num momento necessário para continuarmos a redesenhar a geografia do sistema literário na recente cena brasileira.

\section{NÃO ESTAMOS MAIS NA RENASCENÇA, ONDE SE PINTAVAM RETRATOS DE PIAS GIOCONDAS}

A escolha do conto "Mestre Goshka", de Adriana Lunardi (1996), para esta análise, deu-se por duas razões. A primeira 
diz respeito à sede por desvelar as estratégias narrativas da escritora contemporânea que podem fazer da ficção um instrumento de transgressão, e a segunda pela essência erótica do conto, um subgênero literário que ainda necessita de mais atenção no âmbito acadêmico. Talvez isso se deva ao fato de a literatura erótica ou pornográfica ainda figurar, equivocada e lamentavelmente, num lugar marginal.

"Mestre Goshka" é um dos contos que compõem a antologia inaugural de Adriana Lunardi, As meninas da Torre Helsinque (1996). Nesta obra, encontramos sete contos cujas histórias abordam temas que envolvem as tensões e as sensibilidades da condição feminina - os medos, as angústias, o amor, a sexualidade com seus traumas e prazeres, captados nas narrativas sob a perspectiva da atualidade. Todos os contos, ao retratar as experiências de mulheres, propõem, a partir da representação literária, modos vários de se pensar criativamente o feminino e suas pluralidades.

A obra em verso nesta apreciação narra a vivência de uma jovem estudante com a experiência do autoprazer. Diante da necessidade de custear suas despesas na recém-chegada São Paulo, a narradora-protagonista, cujo nome não é citado, aceita a proposta de posar para um artista plástico, conhecido por Mestre Goshka, nome que intitula o texto. 
Nas primeiras cenas descritas na narrativa, a protagonista já se encontra em uma situação em que seu corpo é evidenciado e julgado por um outro olhar, nesse caso, o olhar de um outro feminino:

Na secretaria, a funcionária complementou as informações cravando as pupilas que, aumentadas pelas grossas lentas da armação preta, giravam inquietas, dando a impressão incômoda de que mediam minhas possibilidades. - Há seis meses procuram candidatas. Muitas já tentaram -, ela fez questão de salientar, excedendo-se em seus pequenos poderes. Encarei-a insubmissa. "Mulheres feias odeiam mulheres bonitas" [...] (LUNARDI, 1996, p. 59)

Como se pode perceber, há a presença da análise do corpo feminino sob duas diferentes óticas: em um primeiro momento, a secretária julga as possibilidades do corpo da protagonista, tentando identificar ao certo se estas cabiam nos moldes desejados pelos padrões de beleza estabelecidos pela sociedade ocidental contemporânea; em um segundo momento, a própria protagonista exerce um juízo de valor ao dizer que as manifestações de comportamento da secretária em relação a ela se fixam na inveja pela ausência daquela mesma beleza padronizada, uma vez que "as feias odeiam as bonitas".

Interessada em estudar teatro, porém sem condições naquele momento, a jovem aceita um trabalho como 
modelo para lhe garantir algum dinheiro. A tônica da narrativa se desenha em torno desta experiência, inusitada e surpreendente, de masturbar-se diante do artista que deseja capturar em sua tela o momento do orgasmo feminino sem a interação com outra pessoa.

Conforme já apontamos, em tempos outros, as experiências femininas foram representadas predominantemente pelo olhar dos homens, os autores. O que temos observado, na contemporaneidade, são os resultados dos movimentos das mulheres que trazem para a cena literária contemporânea as experiências femininas sob seus próprios olhares. Virginia Woolf lembra-nos que, mesmo no século XIX, período em que as mulheres viviam quase exclusivamente em suas casas e em suas emoções, os romances por elas produzidos, ainda que extraordinários, "foram profundamente marcados pelo fato de as mulheres que os escreveram serem excluídas, por seu sexo, de certos tipos de experiências" (WOOLF, 2019, p. 12). Para Woolf, é indiscutível que a experiência de quem escreve exerce grande influência sobre a ficção.

A literatura produzida em momentos passados, mais que uma representação do universo feminino, era na verdade um instrumento para disseminação das convicções 
e dos padrões de conduta esperados para uma "mulher de bem", tais quais as obras pertencentes à Coleção Menina $e$ Moça de Marguerite Froment ${ }^{2}$, por exemplo, que traziam acentuadas lições morais, de um discreto perfume religioso que, nas mãos de todas as adolescentes, tinha a função de diverti-las, encantava-as e, o mais importante, edificava-as para cumprir suas funções domésticas (FROMENT, 1954). Tais textos atendiam, pois, às demandas da sociedade em questão, não se apresentando como voz de representação da figura feminina.

Ao recuperarmos aspectos do passado e ao nos colocarmos diante do que nos é proposto no presente, percebemos o quanto é importante a existência de uma poética feminina e feminista, que dê continuidade à inserção das mulheres escritoras na literatura e as faça circular livres de interdições, que não apenas critique o modo dominante de produção de conhecimento, mas que também proponha novas articulações e reflexões, sobretudo, considerandose as diferenças em suas experiências históricas e culturais em relação ao masculino. Ao olharmos para a afirmação de Woolf, entendemos que a influência do escritor/escritora na ficção não se trata de um ato de colagem da experiência

2 FROMENT, Marguerite. Coleção Menina e Moça. Tradução de Marina R. Lopes. Rio de janeiro: Livraria José Olympio Editora, 1954. 
na obra, trata-se, pois, da influência das experiências que contribuem para o desenvolvimento e manifestação da consciência feminista, conforme assevera Lúcia Helena Vianna (2003):

Por poética feminista se deva entender toda discursividade produzida pelo sujeito feminino que, assumidamente ou não, contribua para o desenvolvimento e a manifestação da consciência feminista, consciência esta que é sem dúvida de natureza política (O pessoal é político), já que consigna para as mulheres a possibilidade de construir um conhecimento sobre si mesmas e sobre os outros, conhecimento de sua subjetividade, voltada esta para o compromisso estabelecido com a linguagem em relação ao papel afirmativo do gênero feminino em suas intervenções no mundo público. Consciência com relação aos mecanismos culturais de unificação, de estereotipia e exclusão. E ainda, a consciência sobre a necessidade de participar conjuntamente com as demais formas de gênero (classe, sexo, raça) dos processos de construção de uma nova ordem que inclua a todos os diferentes, sem exclusões. Poética feminista é poética empenhada, é discurso interessado. É política. (VIANNA, 2003, s.p.)

Entendemos, pois, que "Mestre Goshka" (1996) esteja intimamente relacionado com essa poética feminina e feminista, que traz a experiência de mulheres enquanto protagonistas e escritoras, de modo a desestigmatizar 
questões pouco exploradas na literatura pelo viés erótico. É importante ressaltarmos que não é nossa pretensão nos ater, nos limites deste texto, a uma delimitação categórica do que é uma produção erótica devido às muitas possibilidades de definição deste conceito ou mesmo de sua indefinição pois, como bem observa Durigan, há toda uma "heterogeneidade dos conceitos sobre o que é um texto erótico" (1985, p. 8). Ao utilizarmos este termo, doravante, estaremos nos referindo à explicitude utilizada pela autora para referir-se à representação da sexualidade na narrativa, sendo o sexo o ponto de partida e o ponto de chegada do texto.

Para além de uma divisão categórica, nosso interesse reside na capacidade da autora de desestabilizar a ideia de puritanismo feminino de maneira crítica e criativa ao tecer uma representação diversa do comportamento sexual de mulheres, sobretudo sem a interação com um homem durante o ato. Ao fazer alusão ao sexo, seus encadeamentos e suas possibilidades, Lunardi toca em um tema ainda fraturante para a sociedade ocidental contemporânea. Apresentar um discurso que desconstrói a submissão feminina, sobretudo quando se trata de sexo, ainda pode ser um tabu. A esse respeito, Paulo A. Vieira Júnior (2014), pesquisador do erotismo na literatura de autoria feminina, observa que: 
Por figurar-se apartada da comunicação comum cotidiana, a experiência dos prazeres é comunicada, comumente, a um círculo restrito de indivíduos e em tom de voz que não "ameace" a organização social. Mesmo em uma época como a nossa, assolada pelos discursos sobre a sexualidade, o erotismo figura ainda como assunto tabu, e este é o ponto, essa pletora de discursos nada mais são do que um sintoma dos impulsos de "domesticação" do tema, dado ser ele tratado sob perspectiva científica, objetivando reforçar os laços do casamento ou promover a saúde do corpo e evitar as sexualidades periféricas. (VIEIRA JÚNIOR, 2014, p. 60)

Ao tom de voz que não representa ameaça à organização social a que se refere o estudioso supracitado é que encontramos a contraposição do conto de Lunardi em pauta, que nos parece justamente romper as barreiras do instituído, apresentando um modo alternativo de operação e articulação da formação discursiva que, por vezes, estigmatiza as experiências sexuais das mulheres.

Mas, afinal, já que não estamos mais na Renascença, período em que se pintavam pias Giocondas então, de que modo elas são pintadas na recente cena literária? Se ainda há na atualidade um espaço profícuo para a narrativa, o conto, segundo Alfredo Bosi, cumpre a seu modo o destino da ficção contemporânea, pois "põe em jogo os princípios 
de composição que regem a escrita moderna em busca do texto sintético e do convívio de tons, gêneros e significados" (2015, p. 7). É neste cenário que as Giocondas têm sido configuradas, no espaço onde não se pretende interdições.

Partindo do pressuposto de que a sexualidade em nosso meio é caracterizada pelos limites a ela impostos, lembremo-nos do que nos diz Foucault em $O$ sujeito e o poder (1995). Ele afirma que uma das manifestações de poder e governo sobre as pessoas se deu por meio do controle dos corpos e da sexualidade. Desde o final do século XVI, este controle estaria sendo exercido por meio de um discurso cuidadosamente vigiado que condenou o sexo à interdição e à repressão, retirando-o de sua condição de naturalidade. Essa colocação se faz pertinente porque o conto em análise opera justamente pela transgressão do discurso de regulação criado em torno do sexo, prazer e regulação dos corpos. Diante disso, entendemos a literatura feminina e feminista como necessária, pois abre portas e expõe o caráter realista e normal do prazer feminino. Possibilita às mulheres sentiremse representadas pela fala da personagem narradora e se colocarem diante da normalização do autoprazer.

Na narrativa de Lunardi, a base do contra discurso começa a ser montada já nos primeiros momentos da narrativa, em 
que a narradora-protagonista sinaliza não ser plenamente satisfeita nas interações sexuais com homens. Pelo que se infere do excerto abaixo, há, neste discurso, uma crítica ao sexo centrado no desejo e satisfação do masculino:

Ah! O pecado de hesitar entre um filé ao molho madeira e brochetes ao bacon não teria um número de pontos superior ao de se cobiçar a mulher do próximo na contagem final do inferno? Mesmo concordando que são delitos de diferentes ordens, faz mais efeito para mim uma boa mesa do que uma trepada, quando, em geral, se dá muito mais do que se recebe. (LUNARDI, 1996, p. 60)

A protagonista vai dando sinais de que não é um sujeito passivo e frívolo. A narrativa revela uma mulher que se desprende do convencional, que se reconhece como sujeito e sabe se identificar-, que se torna dona de seu próprio desejo, com pleno acesso ao corpo e ao prazer, sem que haja interferência do outro que a sujeite a um molde falocêntrico, por tantas vezes acessado nas práticas sexuais. Demonstrando postura de protagonismo perante o evento prestes a acontecer, a personagem descreve o que haveria de vestir para aquele momento:

Para visitar o artista, escolhi o vestido courino preto atravessado de cima a baixo por um longo zíper, botas de salto alto e meias de lã sete oitavos que dois anéis elásticos mantinham agarradas a meio caminho da 
coxa. Os homens eram os que mais me olhavam subir e descer as bocas do metrô. Insistiam na atenção, como se lhes fosse reservado por Deus o direito de serem assim inconvenientes com as mulheres. (LUNARDI, 1996, p. 61)

Depreende-se do referido trecho o incômodo que causa à personagem a realidade de que muitos homens se veem munidos de posse, por toda a estrutura enraizada em suas formações identitárias, em relação ao corpo feminino, explicitando a cobiça, a aproximação, e por tantas vezes, o sentimento de domínio sobre os corpos femininos. A relação entre homens e mulheres é moldada nas concepções dos paradigmas morais da sociedade patriarcal; embora haja mudanças significativas nessa interação, muitos ideais ainda imperam e, de certo modo, legitimam comportamentos em torno do masculino, como os descritos anteriormente.

Interessante observarmos, neste conto, o olhar para a mulher pelo viés das artes plásticas. Lembremo-nos de que, assim como na literatura, na pintura produzida no início da cultura burguesa - fins do século XVII, até o final do século XIX -, a representação da mulher também sublimava mensagens sutis de recato e inocência. Essas mensagens, subliminadas na disposição do corpo, na vestimenta e no ambiente assinalavam um modelo a ser seguido conforme os padrões 
da sociedade burguesa capitalista. Bem destoante desses padrões, está a pretensão de Mestre Goshka, que quer representar com sua arte o prazer do corpo especificamente feminino, livre de condenação, sobretudo, por este prazer ser atingido pela prática da automasturbação, sem nenhum tipo de ultraje:

Seus olhos miúdos focavam como se buscasse o calibre certo para as formas do meu corpo. Não me apressava em minha decisão, mas também não facilitava uma resposta. - Não estamos mais na Renascença, onde se pintavam retratos de pias Giocondas, se você ainda não sabe - ele disse [...] (LUNARDI, 1996, p. 64)

O perfil de uma mulher contemporânea um pouco mais autônoma no que respeita ao exercício da sexualidade vai sendo delineado, tanto pelos movimentos do pincel de Mestre Goshka, quanto pelos movimentos da narrativa, que transgridem ao inserir um viés erótico, numa perspectiva artística da sexualidade. Tal perspectiva se encarrega de representar o prazer como um dos meios de autoafirmação identitária das mulheres, desprendidas do puritanismo que as afasta de uma identidade pré-moldada pelo masculino. O erotismo se revela junto a descrição da cena na qual a protagonista dá início ao processo de experimentação que Ihe confere alteridade e a possibilidade de se enxergar não 
apenas como a outra, numa relação homem/mulher, mas enxergar-se a si mesma:

Tudo que era lógico e mesmo previsível em meus gestos e opiniões se dissolvia, rapidamente me desobrigando de ser eu mesma. Agia agora sobre uma nova lei, que prescindia do velho ritual que eu usava para me convencer de minha própria identidade. Eu intuía uma outra, mais impetuosa e esperta, se insinuando pelos mesmos poros e neurônios de sempre. (LUNARDI, 1996, p. 65-66)

Com a autonomia da voz da personagem feminina, a narrativa opera pela manifestação da liberdade de expressão das mulheres. Ao se dar-se experiência do sexo como instrumento de prazer, observamos uma personagem que detém o controle do seu próprio corpo e da relação sexual enquanto sujeito ativo:

Puxei o zíper aos pedaços, olhando para os dois montinhos que se insinuavam curiosos para fora do decote. Minha mão, muito fria, acariciou-os sobre o tecido liso do sutiã, demorando o polegar nos mamilos. Sempre adorei mexer ali. Eram pontos essenciais do meu sentimento de feminilidade. (LUNARDI, 1996, p. 66)

Desmitificando a ideia de que apenas os homens possuem o direito de se automasturbarem, a narrativa expõe um circuito emancipatório que destrói os 
mecanismos repressores da subjetividade feminina e dos padrões existentes até mesmo no terreno da sexualidade. Numa perspectiva natural da exploração do corpo e da experiência erótica, o conto propõe uma forma de perceber a sexualidade feminina desvinculada do falocentrismo:

Me parecia adequado o ritmo frenético dos dedos procurando a verdadeira textura da carne, no inadiável caminho para os pelos que não se continham sob o tecido branco da calcinha. Foi abrindo bem o ângulo das pernas que pensei em uma mulher. A parceira imaginária surgia entre minhas fantasias quando eu precisava de uma personagem adequada a este orgasmo sem falo. Tinha a compreensão da simetria e a delicadeza que o lesbianismo promete. Era uma mulher linda, que encostava os mamilos dos seus seios nos meus, para depois mordêlos com a reverência de um paladar atento. (LUNARDI, 1996, p. 68)

Para além do sentido estético da temática erótica, a narrativa toca também na questão sócio existencial, pois propicia a percepção, através da escrita realizada por uma autora, da expressão do homoerotismo feminino, "da inscrição de uma identidade feminina plural, conscientemente afastada da visão essencialista já cristalizada no mundo ocidental e da qual a própria mulher ainda tem dificuldade de livrar-se" (SOARES, 1999, p. 15). 
Ao acionar para a cena personagens imaginários que vêm incitar o prazer da protagonista, a narrativa se pretende ainda mais instigante, pois traz à tona a multiplicidade existente em torno do sexo. Podemos observar, assim, uma mente desprendida de medidas e padrões engessados, criando personagens que constituem a ruptura com o que esteve posto em cena por muito tempo na representação das mulheres e sua relação com o sexo:

A umidade que me alagava ia preparando uma longa sondagem de dedos. Com o médio, esfreguei-me até sentir um amortecimento que não traduzia o prazer procurado. Deiteime de costas e a vantagem da posição permitia tocar o ânus. Experimentei uma sensação nova exibindo-me para o menino imaginário, por quem eu caprichava nos gestos, mordendo os lábios, tendo convulsões no corpo, concentrada inteira neste ponto lúcido, que parece desconhecer outra vantagem da existência. E então senti que chegava lá, e que sim, a modernidade funcionava para mim. (LUNARDI, 1996, p. 70)

A experiência do prazer solo e a consciência da naturalidade da ação realizada fazem com que a protagonista, despida de suas roupas e tabus, encare a si mesma no espelho e note as "faces avermelhadas e um brilho nos olhos" (LUNARDI, 1996, p. 70) que, segundo ela, não eram de alegria, reconhecendo o desejo e o prazer em relação ao próprio corpo. Talvez 
pela carga de julgamento advinda das regulações sobre o corpo feminino, estruturadas culturalmente, é que a protagonista se veja imersa num universo de contradição, pois ao passo em que fica satisfeita com a experienciação do autoprazer, se permitira enxerga certa monstruosidade na cena: "Sentia fome e vontade de enfiar-me debaixo das cobertas, para dormir, esquecer desta noite, sonhar com o verão, ou qualquer lugar que me resgatasse desta coisa meio monstruosa, meio cínica, que eu acabara de fazer" (LUNARDI, 1996, p. 70).

A intensidade das emoções e toda a circunstância que se delineou provocam inquietação tal que faz com que a mulher saia tomada por um nervosismo latente e bata a porta às suas costas, ao som da voz de Mestre Goshka questionando sobre seu retorno. Desse modo, ao manter o final do conto em aberto e sem nos dar a certeza se ela voltará ao estúdio ou não, Lunardi deixa a cargo do leitor preencher as lacunas e decidir por si só se a protagonista, ao lidar com os sentimentos e sensações novas que se desdobraram daquele encontro, retornará.

\section{DE FATO, “A MODERNIDADE FUNCIONA” PARA NÓS}

Estudar romances e contos da literatura brasileira produzida nas últimas décadas do século XX e no início do 
século XXI permite um alargamento de perspectivas em relação à produção e à recepção de novos autores e de novas obras literárias responsáveis pelo nosso traslado enquanto leitores para o mundo ficcional. Conceder mais atenção à produção de hoje propicia compreender manifestações dos movimentos atuais, de maneira generalizada, bem como observar de que modo esses movimentos são refletidos na produção contemporânea da Literatura Brasileira e suas tendências estéticas.

Ressalte-se que nossa escolha por analisar uma obra de autoria feminina, neste trabalho, não se atrela à pretensão de afirmar a existência de uma linguagem específica de gênero. Temos a compreensão de que a autonomia discursiva das mulheres não afirma a existência de uma linguagem feminina, diferente, em sua essência, da masculina; pretendemos, apenas, mostrar eventuais tendências que predominam no texto da ficcionista.

Empreender leitura à produção de uma autora brasileira contemporânea vai além da possibilidade de apreciação da escritora e de sua obra. A densidade semântica e política da narrativa analisada é muito mais importante para demarcar seu espaço no rol da alta literatura, revelando a potência criativa da escritora e tornando vocal uma categoria que, 
por muito tempo, não pôde assumir seu lugar de fala para se pronunciar, ser ouvida e apresentar sua arte. A autoria feminina é um campo que nos chama a atenção por todo o contexto que envolve a história e a trajetória da literatura, inclusive pelo fato de, ao trazermos para o campo da discussão obras de autoras, cumprirmos o papel de fomentar a notoriedade e reconhecimento da arte literária sob a representação feminina. Interessa-nos, conforme apresentado neste estudo, demonstrar a qualidade estética e literária de autoras que, a exemplo do que fizeram suas precursoras, legitimam a qualidade de suas produções.

"Mestre Goshka" se configura como um espaço de elucidação da experiência feminina por uma vertente consideravelmente necessária, vez que oferece a quem lê a chave de entrada para a compreensão dos mecanismos acionados pela escritora que adentra um universo interdito e, ainda hoje, um tabu: o (auto) prazer feminino. Propondo um desprendimento aos padrões em torno do corpo e das ações femininas, Lunardi abre um espaço de questionamento ao deslocar a temática abordada de um lugar relegado à margem para um lugar central em que a modernidade funciona para a protagonista e para tantas outras mulheres por ela representadas. 
Ainda que construída em torno de uma temática tabu, "Mestre Goshka" é uma construção delicada e poética. Sua tessitura tem o olhar cuidadoso da artesã que articula muito bem sua malha para tecer o literário, permitindo que a qualidade estética e temática se mantenham muito bem realizadas, evidenciando, sobretudo, que a escrita também é um ato de poder.

\section{REFERÊNCIAS}

BOSI, Alfredo. O conto brasileiro contemporâneo. seleção de textos, introdução e notas biográficas por Alfredo Bosi. 16. ed. São Paulo: Cultrix, 2015.

BRANCO, Lúcia Castello; BRANDÃO, Ruth Santiago. A mulher escrita. Rio de Janeiro: Lamparina Editora, 2004.

BRANDÃO, Izabel F. O. Lugares heterotópicos e a constituição de corpos fornteiriços e identidades transitórias na narrativa de autoras contemporâneas. In: DALCASTAGNÉ, Regina. Espaço e gênero na literatura brasileira contemporânea. Porto Alegre: Zouk, 2015. CULLER, Jonathan. Sobre a desconstrução: teoria e crítica do pósestruturalismo. Tradução de Patrícia Burrowes. Rio de Janeiro: Record; Rosa dos Tempos, 1997.

DALCASTAGNÈ, Regina. Literatura brasileira contemporânea: um território contestado. Vinhedo: Editora Horizonte, 2012.

DALCASTAGNÈ, Regina. Representações irrestritas: a mulher no romance brasileiro contemporâneo. In: DALCASTAGNÈ, Regina. Deslocamentos de gênero na narrativa brasileira contemporânea. São Paulo: Editora Horizonte, 2010.

DURIGAN, Jesus Antônio. Erotismo e literatura. São Paulo: Ática, 1985. FOUCAULT Michel. O sujeito e o poder. In: DREYFUS, Hubert e RABINOW, 
Paul (Orgs.). Michel Foucault: Uma trajetória filosófica. Tradução de Vera Porto Carrero. Rio de Janeiro: Forense Universitária, 1995.

LUNARDI, Adriana. Mestre Goshka. In: LUNARDI, Adriana. As meninas da Torre Helsinque. Porto Alegre: Mercado Aberto, p. 57-70, 1996.

SOARES, Angélica. A paixão emancipatória. Rio de Janeiro: DIFEL, 1999.

TELLES, Norma. Encantações: escritoras e imaginação literária no Brasil. 1987 Tese (Doutorado em Ciências Sociais) - Pontifícia Universidade Católica de São Paulo. São Paulo, 1987. Disponível em: https://tede2. pucsp.br/handle/handle/18403 Acesso em: 26. set. 2020.

VIANNA, Lúcia Helena. Poética feminista - poética da memória. Revista Labrys estudos feministas. n. 4, agosto/dezembro de 2013. Disponível em: $\underline{\text { https:// }}$ www.labrys.net.br/labrys4/textos/lucia1.htm. Acesso em: 27 set. 2020.

VIEIRA JÚNIOR, Paulo Antônio. Uma escrita sustentada pela paixão: a poesia erótica de Yêda Schmaltz. 2014. Tese (Doutorado) - Universidade Federal de Goiás. Faculdade de Letras (FL). Programa de Pós-Graduação em Letras e Linguística, Goiânia, 2014. Disponível em: https://repositorio.bc.ufg. br/bitstream/ri/11270/1/Artigo\%20-\%20Paulo\%20Ant\%C3\%B4nio\%20 Vieira\%20J\%C3\%BAnior\%20-\%202015.pdf. Acesso em: 27 set. 2020. WOOLF, Virginia. Mulheres e ficção. Tradução de Leonardo Fróes. São Paulo: Penguin Classics; Companhia das Letras, 2019.

ZINANI, Cecil Jeanine Albert. Crítica feminista: lendo como mulher. Revista Fronteira. São Paulo, n. 7, dezembro de 2011.

\section{Fabrícia dos Santos Silva Martins}

Doutoranda no Programa de Mestrado e Doutorado em Estudos da Linguagem (PPGEL/UFG-RC em transição para UFCAT).

Professora efetiva da Secretaria de Educação do Estado de Goiás/ SEDUCE.

É membro pesquisadora do Grupo de Pesquisa EDULE - Educação, Leitura e Escrita (UFG).

Lattes: $\underline{\text { http://lattes.cnpq.br/4278641674264069 }}$

Email: fabricia.ss.0martins@hotmail.com

ORCID iD: https://orcid.org/0000-0001-5337-7803 


\section{Fernanda Lázara de Oliveira Santos}

Doutoranda em Estudos da Linguagem pela UFG-RC.

É membro pesquisadora do Grupo de Pesquisa cadastrado no CNPq:

EDULE - Educação, Leitura e Escrita (UFG).

Lattes: http://lattes.cnpq.br/5116237865130558

E-mail: fernandalos@gmail.com

ORCID iD: https://orcid.org/0000-0003-0740-9303

\section{Silvana Augusta Barbosa Carrijo}

Pós-doutora pela faculdade de Ciências e Letras de Assis/ UNESP.

Professora Associada II da UFG - RC em transição para UFCAT.

Atua na Graduação em Letras e no Mestrado e Doutorado em Estudos da Linguagem. Integra, na Associação Nacional de Pesquisa e PósGraduação em Letras e Linguística (ANPOLL), o GT Leitura e Literatura Infantil e Juvenil.

É membro pesquisadora dos seguintes Grupos de Pesquisas cadastrados no CNPq: Leitura e Literatura na Escola (UNESP/Assis), EnLIJ - Encontros com a Literatura Infantil/Juvenil: fiç̧ão, teorias e práticas (UERJ), Ensino e Linguagem (URFN) e EDULE - Educação, Leitura e Escrita (UFG). É membro pesquisadora da RELER - Rede de Estudos Avançados em Leitura, do IILER - Instituto Interdisciplinar de Leitura PUC - RIO - Cátedra Unesco de Leitura.

É membro colaboradora externa do Grupo Liter 21 - Literatura Gallega. Literatura Infantil Y Juvenil. Investigaciones literarias, artísticas, interculturales y educativas (Universidade de Santiago de Compostela-ES).

Lattes: $\underline{\text { http://lattes.cnpq.br/5194565631446090 }}$

E-mail: silvana_carrijo@ufg.br

ORCID iD: https://orcid.org/0000-0002-2010-1453 